\title{
Engineering Lipid Overproduction in the Oleaginous Yeast Yarrowia lipolytica
}

Kangjian Qiao ${ }^{\mathrm{a}}$, , Syed Hussain Imam Abidi ${ }^{\mathrm{a}}$ 1, 2, Hongjuan Liu ${ }^{\mathrm{a}}$, Haoran Zhanga ${ }^{\mathrm{a}}$, Sagar Chakraborty $^{\mathrm{a}}$, Nicki Watson ${ }^{\mathrm{b}}$, Parayil Kumaran Ajikumar ${ }^{\mathrm{a}, 3}$ and Gregory Stephanopoulos ${ }^{\mathrm{a}, \text { * }}$

${ }^{a}$ Department of Chemical Engineering, Massachusetts Institute of Technology, Cambridge, Massachusetts 02139; and ${ }^{b}$ Whitehead Institute for Biomedical Research, W.M. Keck Imaging Facility, 9 Cambridge Center, Room 447, Cambridge, MA 02142

1. These authors contributed equally to the work.

2. Current Address: Butazyme Incorporation, 76 Kilmarnock Street, Boston, MA 02215, USA

3. Current Address: Manus Biosynthesis, 1030 Massachusetts Avenue, Suite 300, Cambridge, MA 02138, USA

*. To whom correspondence should be addressed. Email: gregstep@ mit.edu

Mailing address: Department of Chemical Engineering, Massachusetts Institute of Technology, Room 56-469, 77 Massachusetts Avenue, Cambridge, MA 02139. Phone: (617) 253-4583. Fax: (617) 253-3122.

Keywords: biodiesel, metabolic engineering, triacylglycerol, autophagy 


\begin{abstract}
Conversion of carbohydrates to lipids at high yield and productivity is essential for cost-effective production of renewable biodiesel. Although some microorganisms can convert sugars to oils, conversion yields and rates are typically low due primarily to allosteric inhibition of the lipid biosynthetic pathway by saturated fatty acids. By reverse engineering the mammalian cellular obese phenotypes, we identified the delta-9 stearoyl-CoA desaturase (SCD) as a rate limiting step and target for the metabolic engineering of the lipid synthesis pathway in Yarrowia lipolytica. Simultaneous overexpression of SCD, Acetyl-CoA carboxylase (ACC1), and Diacylglyceride acyl-transferase (DGA1) in Y. lipolytica yielded an engineered strain exhibiting highly desirable phenotypes of fast cell growth and lipid overproduction including high carbon to lipid conversion yield $(84.7 \%$ of theoretical maximal yield), high lipid titers $(\sim 55 \mathrm{~g} / \mathrm{L})$, and enhanced tolerance to glucose and cellulose-derived sugars. Moreover, the engineered strain shows a three-fold growth advantage over the wild type strain. As a result, a maximal lipid productivity of $\sim 1 \mathrm{~g} / \mathrm{L} / \mathrm{h}$ is obtained during the stationary phase. Furthermore, we show that the engineered yeast required cytoskeleton remodeling in eliciting the obesity phenotype. Altogether, our work describes the development of a microbial catalyst with the highest reported lipid yield, titer and productivity to date. This is an important step towards the development of an efficient and cost-effective process for biodiesel production from renewable resources.
\end{abstract}


Biodiesel, the primary renewable alternative to diesel, is presently produced almost exclusively from vegetable oils in an overall process that is suboptimal in terms of allocation of scarce land resources (Hill et al., 2006). An alternative is microbial production of oil from renewable feedstocks, however, the choice of microbe and the efficiency of feedstock conversion impact the economic feasibility of fuel production (Zhang et al., 2011). Recently, attention has also been directed towards triacylglycerol (TAG) production from photosynthetic microbes such as algae (Hu et al., 2008; Singh et al., 2011). Despite low-cost carbon feedstocks, oil-producing algae must overcome obstacles of low biomass concentrations and high dewatering costs, high water demand, competition with fast growing species, and high oil recovery costs (Chisti, 2007; Greenwell et al., 2010; Singh et al., 2011). Thus, current efforts are shifting towards the engineering of heterotrophic microbes for the production of renewable oil or fatty acid methyl esters (FAMEs), as this approach can increase the energy yield per hectare of land by an order of magnitude relative to the production of oil crops (Service, 2008; Stephanopoulos and Abidi, 2010).

The challenge is developing a microbial catalyst for high yield conversion of carbohydrates to oils with an industrially-relevant productivity. Recent advances in metabolic engineering and synthetic biology have delivered customized microorganisms that convert renewable feedstocks to biofuel molecules (Atsumi et al., 2008; Lu et al., 2008; Steen et al., 2010). Nonetheless, development of efficient microbial catalysts is hampered by incomplete understanding of the biochemistry of the organisms involved (Dunlop, 2011; Fischer et al., 2008; Hu et al., 2008; Mukhopadhyay et al., 2008; Peralta-Yahya and Keasling, 2010), such as the regulation of fatty acid synthesis and lipid accumulation (Dulermo and Nicaud, 2011; Masoro, 1965). Previous efforts at engineering lipid synthesis have been directed towards increasing the rate of fatty acid synthesis (Lu et al., 2008) and enlarging the supply of pathway precursors (Tai and Stephanopoulos, 2013), 
or tailoring fermentation growth conditions including fatty acid supplementation (Mlickova et al., 2004; Wakil et al., 1983). These approaches have not dealt effectively with one major bottleneck of fatty acid flux, namely, allosteric inhibition of fatty acid biosynthetic enzymes by saturated fatty acids, eliciting a negative feedback response to their own synthesis (Goodridge, 1972; Masoro, 1965; Wakil et al., 1983).

It would be advantageous to consider engineering native heterotrophic microbes with intrinsically evolved capacity to store TAGs. Yarrowia lipolytica is an obligate aerobic, oleaginous yeast capable of accumulating substantial amounts of neutral lipids (mainly TAG) (Papanikolaou et al., 2002). Its genome has been sequenced, facilitating the genetic engineering. $Y$. lipolytica has an evolutionarily advanced carbon to oil flux triggered during stationary growth phase under nitrogen limiting and carbon excess conditions (Papanikolaou et al., 2002). However, intracellular lipid accumulation is sub-optimal, suggesting a tight metabolic regulatory mechanism that controls fatty acid homeostasis (Papanikolaou and Aggelis, 2002; Papanikolaou et al., 2002; Zhao et al., 2010). One strategy by which high fatty acid flux could be sustained without triggering allosteric pathway inhibition is through conversion of saturated to monounsaturated fatty acids and increased sequestration of the pathway products in a fatty acid sink. However, the identity of metabolic regulators, which can modulate fatty acid sequestration remains elusive despite several studies on lipid metabolism, storage and mobilization (Beopoulos et al., 2009; Hu et al., 2008). Here we present the identification of a novel metabolic regulator through the reverse engineering of mammalian fat-storing tissue and overexpression of the regulator lead to enrichment of the intracellular monosaturated fatty acids, which benefits both the cell growth and the sequestrations of fatty acids into the neutral lipids. The engineered $Y$. lipolytica strain was demonstrated to be a 
superior lipid producer which is capable of efficiently transforming glucose or renewable carbohydrates into TAGs at high yield and productivity.

\section{Materials and Methods}

\section{Plasmids and Strains.}

All cloning procedures were carried out in E. coli strain DH5a (New England Biolabs). Genes were all amplified using genomic DNA extracted from Y. lipolytica po1g using Wizard Genomic DNA Purification Kit (Promega). The engineered yeast strains were constructed via transformation of the corresponding plasmid into po1g strain according to manufacturer's protocol (Yeastern). Detailed procedures are provided in Supplementary Information. The primers, plasmids and strains used in the study were respectively listed in Table S5 and Table 1.

\section{SAGE libraries, tissues, fatty acid and related genes.}

The SAGE libraries for non-fat storing and fat accumulating tissues were identified and downloaded from NCBI data repository (http://www.ncbi.nlm.nih.gov/geo/browse/). The SAGE tags for pre-selected fatty acid genes and other regulatory genes were extracted along with locus ID and is shown in Table S1. The corresponding library sizes and gene expression omnibus accession are summarized in Table S2.

\section{Culture Conditions and Analysis.}

E. coli strains were grown at $37{ }^{\circ} \mathrm{C}$ in LB medium supplemented appropriate antibiotics (ampicillin $100 \mu \mathrm{g} / \mathrm{mL}$ and kanamycin $50 \mu \mathrm{g} / \mathrm{mL}$ ). Shake flask fermentations of $Y$. lipolytica were carried out with $250 \mathrm{~mL}$ conical flasks containing $50 \mathrm{~mL}$ defined cell culture medium $(1.7 \mathrm{~g} / \mathrm{L}$ yeast nitrogen 
base without amino acid and ammonium sulfate, $50 \mathrm{~g} / \mathrm{L}$ glucose and $2.2 \mathrm{~g} / \mathrm{L}$ ammonium sulfate). The cells were grown at $30{ }^{\circ} \mathrm{C}$ at $200 \mathrm{rpm}$ for 120 hours, when the cells were harvested for dry cell weight and lipid measurement. The cell growth was measured every 24 hours by optical density at $600 \mathrm{~nm}$.

Scale-up fermentations were performed in $3 \mathrm{~L}$ (1.5 L working volume) Bioflo 115 bioreactor (Eppendorf) containing $3.4 \mathrm{~g} / \mathrm{L}$ yeast nitrogen base without amino acids and ammonium sulfate, $150 \mathrm{~g} / \mathrm{L}$ glucose, $2 \mathrm{~g} / \mathrm{L}$ yeast extract, and $8.8 \mathrm{~g} / \mathrm{L}$ ammonium sulfate. Oxygen was supplied in the form of filtered air via sparging rate of $1-5 \mathrm{~L} / \mathrm{min}$ of air using agitation in 200-800 rpm range to maintain dissolved oxygen levels above $20 \%$ during growth phase $(0-48 \mathrm{~h})$ and $0-5 \%$ at stationary phase. The temperature was maintained at $28{ }^{\circ} \mathrm{C}$ and the $\mathrm{pH}$ of the culture was constantly controlled at 5.50 using $10 \% \mathrm{KOH}$.

Biomass was dried in oven at $90{ }^{\circ} \mathrm{C}$ to moisture content $<1 \%$ and dried biomass measured using the analytical balance. Sugars such as glucose and extracellular metabolites, for example citrate, were measured in a high-performance liquid chromatography (HPLC) system with a Waters 2690 separations module connected to a Waters 410 refractive index detector (Waters). The samples were separated on a BioRad Aminex HPX-87H ion exclusion column for organic acid analysis with $14 \mathrm{mM}$ sulfuric acid as the mobile phase at a flow rate of $0.7 \mathrm{~mL} / \mathrm{min}$.

\section{Total RNA isolation and quantitative PCR analysis.}

The total RNA $(100 \mu \mathrm{g})$ was isolated from $3 \times 10^{8}$ growing yeast cells obtained from shaking flask cultures (42 h) using the RiboPure-Yeast kit (Ambion). The RNA was digested with 8 U DNase I at $37^{\circ} \mathrm{C}$ for 1 hour to remove the residual DNA contaminations. RNA quantity was analyzed using a NanoDrop ND-1000 spectrophotometer (NanoDrop Technologies, Wilmington, DE) and 
samples were stored in $-80{ }^{\circ} \mathrm{C}$ freezer. $0.5 \mu \mathrm{g}$ of DNase I-treated RNA samples were reverse transcribed to double-strand DNA using ImProm-IITM Reverse Transcription kit (Promega) and random hexamer for $60 \mathrm{~min}$ at $42{ }^{\circ} \mathrm{C}$ according to the manufacturer's instructions. The reaction was quenched by incubation at $70^{\circ} \mathrm{C}$ for $10 \mathrm{~min}$.

The cDNA levels were then quantified using a Biorad iCycler 4 Real-Time PCR Detection System (Bio-Rad) with SYBR Green I detection. Each sample was measured in triplicate in a 96-well plate (VWR) in a reaction mixture (30 $\mu \mathrm{L}$ final volume) containing $1 \times$ XtensaMix-SG (BioWORKS), $200 \mathrm{nM}$ primer mix (shown in Table S), $2.5 \mathrm{mM} \mathrm{MgCl}_{2}$, and $0.75 \mathrm{U}$ of Taq DNA polymerase (New England Biolabs). Real time PCR was performed with an initial denaturation of 3 min at $95^{\circ} \mathrm{C}$, followed by 30 cycles of $20 \mathrm{~s}$ at $95^{\circ} \mathrm{C}, 20 \mathrm{~s}$ at $60^{\circ} \mathrm{C}$, and $20 \mathrm{~s}$ at $72{ }^{\circ} \mathrm{C}$. Fluorescent detection was performed at the annealing phase and during subsequent dissociation curve analysis to confirm that a single product had been amplified. The threshold cycles $(\mathrm{Ct})$ were calculated using the iQ5 Optical system software version 2.0. Primer dimers in all the assays showed distinct melt characteristics from the desired amplicons. All real-time PCR quantifications were performed simultaneously with PCR amplified standards and no-template controls. Absolute gene copy numbers for each gene were interpolated from standard curves. All samples were analyzed in triplicates.

\section{Lipid Extraction and Quantification.}

To measure intracellular lipid amounts, $\sim 2 \mathrm{mg}$ of $Y$. lipolytica cells were harvested and washed in fresh distilled water twice. Then, the dried samples were added $500 \mathrm{uL}$ methanol solution containing $1 \mathrm{M} \mathrm{NaOH}$. The samples were vortexed at $1200 \mathrm{rpm}$ at room temperature for 1 hour. Then the solution was neutralized with $40 \mu \mathrm{L}$ sulfuric acid and $500 \mu \mathrm{l}$ hexane was added to extract 
the fatty acid methyl esters (FAMEs). All mixtures were separated by centrifuging at $8000 \mathrm{rpm}$ for 2 min and $1 \mu \mathrm{l}$ of the top hexane layer was subjected to be analyzed using the Bruker 450 gas chromatography equipped with a flame ionization detector and a capillary column HP-INNOWAX (30 $\mathrm{m}, 0.25 \mathrm{~mm}$ ) according to the procedure previously reported (Tai and Stephanopoulos, 2013).

For extracting FFA from engineered yeast, cells were lysed and extracted with 2:1 v/v chloroform-methanol $(4 \mathrm{~mL})$ for total lipids. The extract was evaporated to dryness under nitrogen stream and re-suspended in $2 \mathrm{~mL}$ of chloroform. Separation of FFAs from esterified fatty acids (triglycerides and phospholipids) in lipidic yeast extracts was achieved using bonded phase aminopropyl-silica SPE cartridges (Discovery DSC-NH2, $100 \mathrm{mg}, 1 \mathrm{~mL}$, Sigma-Aldrich). The cartridge was conditioned with chloroform $(3 \mathrm{~mL})$ and each lipidic yeast extract $(0.5 \mathrm{~mL})$ loaded onto a cartridge. The cartridges were washed with $2: 1 \mathrm{v} / \mathrm{v}$ chloroform-2- propanol $(1 \mathrm{~mL})$ and FFAs eluted with 98:2 v/v diethyl ether (DEE)-acetic acid ( $3 \mathrm{~mL}$ ) into $5 \mathrm{~mL}$ graduated glass tubes. Contents of the tubes were transferred quantitatively to $12 \mathrm{~mL}$ borosilicate glass tubes, using 98:2 v/v DEE-acetic acid solution (1 mL). The DEE extract was evaporated to dryness (10 min, $\left.45^{\circ} \mathrm{C}\right)$ under nitrogen stream and converted to FAME as described above. Sample residues were reconstituted in hexane ( $3 \mathrm{~mL}$ ) and quantified by GC-FID analysis.

\section{GC-FID analysis for fatty acid identification and quantification.}

For the analysis of FAMEs, we used a Bruker 450 GC equipped with a flame-ionization detector and a capillary column HP-INNOWAX (30 $\mathrm{m} 0.25 \mathrm{~mm})$. One $\mu \mathrm{L}$ of sample was injected in a 10:1 split mode at $275{ }^{\circ} \mathrm{C}$, using helium as the carrier gas at a flow rate of $1 \mathrm{~mL} / \mathrm{min}$. The $\mathrm{GC}$ oven temperature was held at $150{ }^{\circ} \mathrm{C}$ for $1 \mathrm{~min}$ and ramped to $230{ }^{\circ} \mathrm{C}$ (rate: $15{ }^{\circ} \mathrm{C} / \mathrm{min}$, hold: $2 \mathrm{~min}$ ) for a total run time of approximately 13.5 min. Different fatty acid methylesters: methyl palmitate 
(C16:0), methyl palmitoleate (C16:1), methyl stearate (C18:0), methyl oleate (C18:1), methyl linoleate (C18:2) were identified and characterized using authentic FAME standards purchased from Sigma-Aldrich. Total lipid titer was quantified as the sum of total fatty acid concentrations of the five FAMEs, which were normalized by the supplemented internal standards methyl tridecanoate and glyceryl triheptadecannoate (Sigma-Aldrich).

Fluorescence and Electron Microscopy. Nikon 80i upright microscope was used to capture DIC and fluorescence images at 100-1000x oil immersion magnification. YL-wt and YL-ad9 cells were stained with nile red dye $(0.1 \mu \mathrm{g} / \mathrm{ml}$ for $5 \mathrm{~min})$. Samples were excited with the $488 \mathrm{~nm}$, and fluorescent emission spectra analyzed in the wavelength region of $525 \mathrm{~nm}$. For electron microscopy the cells were fixed for 1 hour at room temperature in (2\% gluteraldehyde, $0.1 \mathrm{M}$ cacodylate, and $5 \mathrm{mM} \mathrm{CaCl}_{2}$ ). One set of cells were spheroplasted, one half of cells were left intact. Cells were then embedded in agarose and cut into small pieces. Blocks were post fixed in $1 \%$ Osmium with $0.1 \%$ potassium ferrocyanide in $0.1 \mathrm{M}$ cacodylate with $5 \mathrm{mM} \mathrm{CaCl}_{2} 30$ minutes at room temperature. After washing thoroughly cells were transferred to $1 \%$ thiocarbohydrazide for 5 minutes at room temperature, followed by $1 \%$ osmium / potassium ferrocyanide mixture. Cells were dehydrated in a graded series of ethanol, followed by propylene oxide and embedded in low viscosity Spurrs resin. Blocks were sectioned on a Leica ultra cut UCT, stained with $2 \%$ uranyl acetate and Reynolds lead citrate, and were viewed at $80 \mathrm{Kv}$ using a FEI Technai Spirit Transmission electron microscope.

\section{Results and Discussion}

\section{Reverse Engineering of Mammalian Fat-storing Tissues.}


To identify potential metabolic lipid regulators, we systematically analyzed key metabolic genes related to fatty acid and lipid synthesis (Table S1) in specialized mammalian lipid-storing tissues. We employed the serial analysis of gene expression (SAGE) method for comprehensive profiling of gene expression patterns with digital analysis. We compiled SAGE data from the publicly available Gene Expression Omnibus (GEO) database (http://www.ncbi.nlm.nih.gov/geo/browse/, accessed 05 Oct, 2013) for normalized tissue libraries for fat-storing (e.g., adipose, liver) and nonfat storing (e.g., lungs, heart) tissues (Fig. S1). Figure 1A shows the transcriptional levels of SAGE tags corresponding to the selected genes in mouse SAGE tissue libraries. The sequenced library sizes of the SAGE tissues are provided in Table S2. Among the genes profiled, stearoyl-CoA desaturase (SCD), a central metabolic regulatory enzyme in lipid metabolism that catalyzes the $\Delta 9$-desaturation of the saturated fatty acids palmitate and stearate to palmitoleate and oleate, respectively (Flowers and Ntambi, 2008), emerged as an important candidate gene for lipogenesis. We hypothesized that SCD might play a key regulatory role in lipid metabolism because, (i) SCD is overexpressed in lipid-storing tissue types (transcript count increased up to 1800 fold compared to other gene sets in the fat tissues) (Fig. 1A); (ii) SCD is not associated with the core lipid or fatty acid biogenesis pathway and therefore unlikely to be negatively regulated by fatty acid end product; and, (iii) elevated SCD can maintain forward fatty acid biosynthetic flux in sustainable activation mode by continuously converting inhibitory saturated fatty acids to mono-unsaturated fatty acids; as a result, lipogenesis can be sustained when combined with concurrent fatty acid sequestration into organism-intrinsic TAG storage lipid bodies. Previous studies have shown that SCD is essential for lipogenesis (Flowers and Ntambi, 2008), and that knockout of SCD gene in mice led to reduced lipid production and body adiposity (Ntambi et al., 2002). 


\section{Overexpression of SCD in oleaginous yeast $Y$. lipolytica.}

To implement the identified target, we over-expressed SCD in Y. lipolytica by introducing a native copy of the SCD gene using a hybrid promoter, which is not repressed by the preferred carbon and nitrogen sources or acidic conditions (Madzak et al., 2000). The ratio of saturated to unsaturated fatty acids in SCD-overexpressed strain YL-D9 was shown to be decreased as a result of converting palmitic and stearic acid substrates to the respective monounsaturated fatty acids by SCD (Fig. S2). However, the YL-D9 strain did not show a lipid hyper-producing phenotype, indicating that solely overexpressing SCD does not lead to the 'obese' phenotype observed in the analyzed mammalian cell lines. In order to test the hypothesis that the function of SCD is exemplified in the background of a high lipid accumulation pathway, we further overexpressed the SCD in the background of the previously engineered MTYL065 strain, in which both ACC1 and DGA1 were overexpressed (Tai and Stephanopoulos, 2013), yielding strain YL-hr3. Fluorescence microscopy of intracellular stored lipids stained with Nile red dye confirmed an extremely "obese" phenotype in YL-hr3 strain (Fig. S3) while shake flask fermentations showed significant growth advantage ( $\sim 3$ fold increase in exponential growth rate, Fig. S4) and improved lipid titer in YLhr3 over both YL-wt and MTYL065 (Fig. 1B)

The genotype of YL-hr3 was confirmed by whole genome re-sequencing and demonstrated the duplications of ACC1, DGA1 and SCD genes along with 11 other structural variations relatively to the base strain po1g (Table S3). Although ACC1, DGA1 and SCD genes were thus confirmed to contribute synergistically to the obesity phenotype of the engineered $Y$. lipolytica, we further constructed a new engineered Y. lipolytica (YL-ad9) strain by co-overexpressing the three lipogenic genes in the genetic background of the base strain polg. This was done by introducing an additional copy of each gene under a strong constitutive TEF-intron promoter to 
po1g strain. The transcription levels of ACC1, DGA1 and SCD genes in YL-hr3 and the newly constructed YL-ad9 strain were found to be increased in both strains and enhanced by 8, 30 and 2.6 fold in YL-ad9 compared to those of YL-wt strain (Figs. S5 and 1). Shake flask fermentations confirmed that YL-ad9 maintains the fast-growth phenotype of YL-hr3 (Fig. S7), thus demonstrating that D9 overexpression in the background of an enhanced lipid synthesis pathway (mediated by ACC1 and DGA1 overexpression) are sufficient to boost yeast growth under lipid accumulation culturing conditions. Moreover, an apparent increase $(25 \%)$ in terms of lipid content was observed in YL-ad9 over YL-hr3 and MTYL065 (Fig. S8), likely due to higher ACC1 and DGA1 levels caused by the use of strong TEF intron promoters (Fig. 1). These findings support the hypothesis that increased monounsaturated fatty acid flux is coupled to increased sequestration into intracellular TAG storage and that the SCD gene has a conserved lipid regulatory role in simple eukaryotes similar to that in mammalian cells.

We also observed a significantly increased tolerance of the YL-ad9 strain to high glucose concentrations $(300 \mathrm{~g} / \mathrm{l})$ compared to the YL-wt, for which cell growth was considerably suppressed at glucose concentrations greater than $150 \mathrm{~g} / \mathrm{l}$ (Fig. S9). As expected, the fraction of each unsaturated fatty acid component with respect to the total is significantly increased while the level of the saturated fatty acid content is slightly increased, suggesting an enhanced flux through the fatty acid pathway (Fig. S10).

\section{Fed-batch Fermentation Performance of YL-ad9 on Glucose.}

We further evaluated the growth and lipid production characteristics of the YL-ad9 strain in a 1.5L bioreactor in defined media with glucose as sole carbon-energy source using the wild type strain YL-wt as a control. A remarkable 4-fold growth rate enhancement was observed during 
exponential growth $(20 \mathrm{~h}-41 \mathrm{~h})$ of the YL-ad9 strain relatively to the YL-wt in the fed-batch fermentations with complete sugar consumption within 78 hours (Fig. 2A). The faster growth observed in YL-ad9 is correlated with the enrichment of mono-unsaturated fatty acid content, presumably due to the enrichment of oleic acid, the major constitute of membrane and the removal of the inhibitory effect of saturated fatty acids on cell growth. This is likely followed by flux diversion to membrane biogenesis during exponential growth phase. A similar pattern is observed in eukaryotic cancer cells where SCD gene up-regulation correlates with increase cancer biomass. The increase in cancerous biomass is consistent with the observation that ablation of SCD expression dramatically impairs proliferation and growth in eukaryotic cancer cells (Scaglia et al., 2009; Swinnen et al., 2000).

Neutral lipid production in the YL-ad9 strain peaked during stationary phase approaching $55 \pm 2.5 \mathrm{~g} / \mathrm{L}$ (measured as FAME) at the end of the fermentation (Fig. 2A No lipids or glucose time courses shown for the wt control). Lipid composition, measured as FAME using GC-FID, showed $71 \%$ oleic acid and $8 \%$ palmitoleic acid content consistent with SCD substrate promiscuity (Fig. S11) (Miyazaki and Ntambi, 2003). Increased mono-unsaturated fatty acid content, such as oleic acid, is preferred in the biofuel industry because of better cold flow properties and reduction of the tendency towards crystallization (Yousuf et al., 2010). The sugar to lipid (measured as FAME) conversion yield was $0.266 \mathrm{~g} / \mathrm{g}$ in stationary phase $(40 \mathrm{~h}-78 \mathrm{~h} ; 96.4 \%$ of the theoretical maximum $0.276 \mathrm{~g} / \mathrm{g}$ ) (Ratledge, 2014). If the entire process is taken into account, including glucose used for cell growth, the yield is $0.234 \mathrm{~g} / \mathrm{g}(84.7 \%$ of the theoretical maximum). Minimizing byproduct citrate formation by limiting dissolved oxygen level to $5 \%$ of saturation during stationary phase contributed to the increase of carbon yield in the bioreactor run. Dry cell weight along with lipidfree biomass and lipid titer are shown in Figure S12. The total lipid yield of the YL-ad9 strain 
represents a 2.93-fold increase compared to the YL-wt under the glucose concentrations used in this study. Due to the greatly improved growth rate and sugar tolerance, the fermentation operation time was reduced to $\sim 78 \mathrm{~h}$ compared to $120-144 \mathrm{~h}$ (Tai and Stephanopoulos, 2013). As a result, YL-ad9 features an overall productivity of $0.707 \mathrm{~g} / \mathrm{L} / \mathrm{h}$ with the maximal productivity close to 1 $\mathrm{g} / \mathrm{L} / \mathrm{h}$, which is 3.5 to 5 fold better than other previously reported engineered $Y$. lipolytica strains under similar bioreactor conditions (Blazeck et al., 2014; Tai and Stephanopoulos, 2013).

It is known that $Y$. lipolytica can accumulate lipids up to 38 to $50 \%$ of its dry cell mass using fatty acid supplementation (Beopoulos et al., 2009; Papanikolaou and Aggelis, 2002). In contrast, the YL-ad9 strain showed up to $67 \%$ lipid content grown on glucose alone. We further tested cell viability and TAG mobilization in the YL-ad9 strain by exposing stationary phase starved cells to fresh nutrients with $160 \mathrm{~g} / \mathrm{l}$ glucose in a 1.5 -L bioreactor. Upon nutrient replenishment cells promptly re-entered mitotic cell cycle division reminiscent of log phase rapid growth coupled with continuous TAG production with complete sugar consumption within 72 hours. Interestingly, intracellular TAG imaging analysis of stationary phase YL-ad9 and YL-wt inoculums (Fig 2C, D) showed two atypical phenotypes during the log phase culture: (i) unlike YL-wt hyphae-shaped cells (Fig. 2F), the YL-ad9 cells retained spherical phenotype (Fig. 2E), and (ii) compared to YL-wt re-mobilization of lipid bodies, the YL-ad9 cells continued to preserve approximately $2 / 3$ rd cell volume with intracellular oil (Fig. 2E, F). These results suggest that the YL-ad9 strain retained viability and "plasticity" for transiting between cell proliferation and growth arrested stages (maximal TAG) and that significant amounts of intracellular lipid are not mobilized from a previous stationary-primed phase. More studies are required to decipher the observed role of SCD in continuous TAG production and mobility and altered morphogenic characteristics. 
A proposed mechanism for SCD-mediated high biomass production and extreme obesity is depicted in Figure 3. The potent allosteric inhibition of ACC1 promoting its depolymerization, is mediated by saturated fatty acyl-CoAs with 16-20 carbons (Ashcraft et al., 1980; Clarke and Salati, 1985; Goodridge, 1972). Over-expression of the D9 draws the fatty acid pathway forward by relieving the palmitoyl-CoA and stearoyl-CoA-mediated inhibition of ACC1. However, a sink is needed for predominant oleoyl-CoA to prevent inhibition of the D9 itself (Minville-Walz et al., 2012). It has been established that monounsaturated fatty acyl-CoAs are preferred substrates over saturated fatty acyl-CoAs (SFAs) for acylation reactions in lipid biosynthesis (Coleman and Lee, 2004; Li et al., 2010). During growth, the primary sink for fatty acids (phospholipids) is membrane synthesis. However, during stationary phase, induced upon nitrogen depletion, intracellular TAG accumulation serves as the main fatty acid pathway sink. The outcome is higher biomass density and extreme lipid accumulation in the YL-ad9 strain. Thus, in order to sustain the continuous flow of substrates required for high lipogenesis, it is necessary to remove SFA accumulation concomitant to lipid production and storage. Consistent with this hypothesis, we observed an increased ratio of unsaturated fatty acids over saturated fatty acids beginning in early growth phase and proceeding to stationary phase (Fig. S13). SFAs are also naturally acylated to TAGs but, through SCD-mediated conversion, the inhibitory SFA levels are further reduced. Hence, suboptimal lipogenesis is removed in the YL-ad9 cells. In addition, the observed robust growth phenotype and high sugar tolerance can be attributed to the increased oleic acid (C18:1) content that has been associated with increased membrane fluidity and osmotic stress tolerance (Swan and Watson, 1999; You et al., 2003). Taken together, these results demonstrate an effective metabolic engineering of oleaginous yeast for high yield and productive conversion of glucose to lipids (Fig. S14). 


\section{Batch Fermentations of YL-ad9 on Cellulosic Plant Biomass and Crude Glycerol.}

A primary goal in renewable energy is the production of biodiesel from cellulosic plant biomass and alternative carbon sources such as crude glycerol. A difficulty in utilizing cellulosic biomass is the generation, during pretreatment, of toxic soluble compounds like acetic acid and furfural, which inhibit growth and sugar utilization of microorganisms during fermentation (Cheng et al., 2008). We subjected the cellulosic fraction of acid pre-treated corn stover provided by the National Renewable Energy Laboratory (NREL) to enzymatic hydrolysis and the resulting liquor (Table S4) containing $102 \mathrm{~g} / \mathrm{l}$ soluble sugars was used to ferment YL-ad9 strain in $1 \mathrm{~L}$ shake flask without a lime detoxification step. After a lag phase of 20 hours, robust growth of the engineered strain was observed demonstrating tolerance to inhibitors that are typically found in acid dydrolysate with high biomass production and $0.14 \mathrm{~g} / \mathrm{g}$ TAG production yield (Fig. 4A). The lower oil yield could be due to high nitrogen content in the corn-derived medium (which would reduce the sugar-to-oil flux), or to the presence of compounds that are inhibitory to oil synthesis. In addition to cellulosic biomass, crude glycerol derived from the biodiesel industry is presently a low-cost carbon feedstock that can be used for microbial oil production. The crude feedstock contains significant fatty-soap and methanol as impurities imparting growth restrictions on microbes. We grew the YLad9 strain in a 1.5 L-bioreactor containing $150 \mathrm{~g} / \mathrm{l}$ crude glycerol with no prior detoxification step. Excellent growth and lipid production was observed with the YL-ad9 strain while the YL-wt marginally grow in high glycerol concentration (Fig. 4B). Glycerol was completely consumed within 84 hours with lipid concentration of $35 \mathrm{~g} / \mathrm{l}$ and overall $0.23 \mathrm{~g} / \mathrm{g}$ TAG production yield.

\section{Probe the Role of Autophagy in Lipid Accumulation.}


To better understand the mechanistic regulation of TAG accumulation during stationary phase, we examined the dramatic cytoplasmic restructuring required to accommodate the growing lipid body during nitrogen starvation. While TAGs in the wild type cells approximately occupy only $1 / 3 \mathrm{rd}$ of the cellular volume, nearly the entire cell is occupied by one large TAG droplet in the mutant (Figure. S3). The most significant event that coincides with nitrogen starvation induced TAG accumulation is autophagy (Takeshige et al., 1992), which is a tightly regulated cytoplasmic and organelle remodeling process to maintain cellular homeostasis and is conserved from yeast to humans (Mizushima, 2007; Nakatogawa et al., 2009). We therefore used high resolution transmission electron microscopy to confirm autophagy-mediated cytoplasmic remodeling in the engineered cells at pre-stationary and late-stationary life cycle (Fig. 5A). Whereas cellular organelles including mitochondria, nuclear membrane and small lipid bodies were prevalent in pre-stationary stage, the enhanced lipid accumulation in later stages caused complete restructuring of cytoplasm with selective preservation and expansion of lipid body and removal of most other organelles (Fig. 5A). Further, by blocking autophagic responses in the YL-ad9 strain via 3methyladenine, a potent and specific autophagic inhibitor (Seglen and Gordon, 1982), TAG accumulation was significantly reduced despite SCD-mediated fatty acid deregulation (Fig. 5C). This suggests that autophagy is a necessary component of high TAG accumulation. In contrast YL-ad9 treated by rapamycin, a potent inducer of autophagy in mammalian cells and yeast (Sarkar et al., 2009), not surprisingly, did not affect (maximal) TAG accumulation suggesting that high fatty acid flux is sufficient to sustain strong autophagic response (Fig. 5B, D). In summary, the above findings suggest autophagy is a necessary but not sufficient element of high TAG accumulation and that de-regulated high fatty acid flux, end product lipid sequestration and autophagy are all indispensable components for eliciting an obesity phenotype in oleaginous yeast. 


\section{Conclusions.}

We report the identification of a conserved fatty acid regulator from specialized mammalian cell types and its ability to elicit similar obese phenotype in much simpler unicellular oleaginous yeast. The growth and lipid accumulation improvements conferred by SCD overexpression require the ACC1-DGA1 overexpression background that produces the high flux through the fatty acid pathway. Moreover, the YL-ad9 yeast displayed multiple phenotypes including fast growth, high sugar tolerance and TAG conversion yield with oil productivity of $22 \mathrm{~kg} / \mathrm{m}^{3} / \mathrm{day}(\sim 11.5$ fold improvement) compared to $1.92 \mathrm{~kg} / \mathrm{m}^{3} /$ day reported in wild type strain (Kosa and Ragauskas, 2011). It should however be noted that volumetric production rates are one third that of ethanol and therefore the process requires further optimization in future research. Therefore, our report represents a significant step toward mitigating major barriers in the commercialization of biodiesel production from scalable feedstocks through modulating the regulatory part of pathway engineering.

\section{Acknowledgements}

We thank Dr. Catherine Madzak, from INRA Micalis Institute, Thiverval Grignon, France for useful discussions and providing critical protocols for yeast transformation and gene expression experiments. We thank Dr. Kang Zhou for useful discussions on quantitative PCR and bioreactor experiments. We also thank National Renewable Energy Laboratory (NREL) for providing cellulosic biomass hydrolyzate and GENENCOR for providing cellulosic enzymes for this study. We acknowledge support from Department of Energy grant number 6922111 and 6926611. Patent 
application US2011/0223641A1 relevant to this paper was filed through Massachusetts Institute

of Technology. SHIA and GS are listed as co-inventors in these patents.

\section{References}

Ashcraft, B. A., Fillers, W. S., Augustine, S. L., Clarke, S. D., 1980. Polymer-protomer transition of acetylCoA carboxylase occurs in vivo and varies with nutritional conditions. The Journal of biological chemistry. 255, 10033-5.

Atsumi, S., Cann, A. F., Connor, M. R., Shen, C. R., Smith, K. M., Brynildsen, M. P., Chou, K. J., Hanai, T., Liao, J. C., 2008. Metabolic engineering of Escherichia coli for 1-butanol production. Metabolic engineering. 10, 305-11.

Beopoulos, A., Cescut, J., Haddouche, R., Uribelarrea, J. L., Molina-Jouve, C., Nicaud, J. M., 2009. Yarrowia lipolytica as a model for bio-oil production. Prog Lipid Res. 48, 375-387.

Blazeck, J., Hill, A., Liu, L., Knight, R., Miller, J., Pan, A., Otoupal, P., Alper, H. S., 2014. Harnessing Yarrowia lipolytica lipogenesis to create a platform for lipid and biofuel production. Nature communications. 5, 3131.

Cheng, K. K., Cai, B. Y., Zhang, J. A., Ling, H. Z., Zhou, Y. H., Ge, J. P., Xu, J. M., 2008. Sugarcane bagasse hemicellulose hydrolysate for ethanol production by acid recovery process. Biochem Eng J. 38, 105-109.

Chisti, Y., 2007. Biodiesel from microalgae. Biotechnology advances. 25, 294-306.

Clarke, S. D., Salati, L. M., 1985. Fatty acid-mediated disaggregation of acetyl-CoA carboxylase in isolated liver cells. Federation proceedings. 44, 2458-62.

Coleman, R. A., Lee, D. P., 2004. Enzymes of triacylglycerol synthesis and their regulation. Prog Lipid Res. 43, 134-176.

Dulermo, T., Nicaud, J. M., 2011. Involvement of the G3P shuttle and beta-oxidation pathway in the control of TAG synthesis and lipid accumulation in Yarrowia lipolytica. Metabolic engineering. 13, 48291.

Dunlop, M. J., 2011. Engineering microbes for tolerance to next-generation biofuels. Biotechnology for biofuels. 4, 32 .

Fischer, C. R., Klein-Marcuschamer, D., Stephanopoulos, G., 2008. Selection and optimization of microbial hosts for biofuels production. Metabolic engineering. 10, 295-304.

Flowers, M. T., Ntambi, J. M., 2008. Role of stearoyl-coenzyme A desaturase in regulating lipid metabolism. Current opinion in lipidology. 19, 248-56.

Goodridge, A. G., 1972. Regulation of the activity of acetyl coenzyme A carboxylase by palmitoyl coenzyme A and citrate. The Journal of biological chemistry. 247, 6946-52.

Greenwell, H. C., Laurens, L. M. L., Shields, R. J., Lovitt, R. W., Flynn, K. J., 2010. Placing microalgae on the biofuels priority list: a review of the technological challenges. J R Soc Interface. 7, 703-726.

Hill, J., Nelson, E., Tilman, D., Polasky, S., Tiffany, D., 2006. Environmental, economic, and energetic costs and benefits of biodiesel and ethanol biofuels. Proc Natl Acad Sci USA. 103, 11206-10.

http://www.ncbi.nlm.nih.gov/geo/browse/, accessed 05 Oct, 2013.

Hu, Q., Sommerfeld, M., Jarvis, E., Ghirardi, M., Posewitz, M., Seibert, M., Darzins, A., 2008. Microalgal triacylglycerols as feedstocks for biofuel production: perspectives and advances. Plant J. 54, 621639.

Kosa, M., Ragauskas, A. J., 2011. Lipids from heterotrophic microbes: advances in metabolism research. Trends in biotechnology. 29, 53-61.

Li, L. O., Klett, E. L., Coleman, R. A., 2010. Acyl-CoA synthesis, lipid metabolism and lipotoxicity. Biochimica et biophysica acta. 1801, 246-51. 
Lu, X., Vora, H., Khosla, C., 2008. Overproduction of free fatty acids in E. coli: implications for biodiesel production. Metabolic engineering. 10, 333-9.

Madzak, C., Treton, B., Blanchin-Roland, S., 2000. Strong hybrid promoters and integrative expression/secretion vectors for quasi-constitutive expression of heterologous proteins in the yeast Yarrowia lipolytica. Journal of molecular microbiology and biotechnology. 2, 207-16.

Masoro, E. J., 1965. Mechanisms related to the homeostatic regulation of lipogenesis. Annals of the New York Academy of Sciences. 131, 199-206.

Minville-Walz, M., Gresti, J., Pichon, L., Bellenger, S., Bellenger, J., Narce, M., Rialland, M., 2012. Distinct regulation of stearoyl-CoA desaturase 1 gene expression by cis and trans C18:1 fatty acids in human aortic smooth muscle cells. Genes \& nutrition. 7, 209-16.

Miyazaki, M., Ntambi, J. M., 2003. Role of stearoyl-coenzyme A desaturase in lipid metabolism. Prostaglandins, leukotrienes, and essential fatty acids. 68, 113-21.

Mizushima, N., 2007. Autophagy: process and function. Genes \& development. 21, 2861-73.

Mlickova, K., Roux, E., Athenstaedt, K., d'Andrea, S., Daum, G., Chardot, T., Nicaud, J. M., 2004. Lipid accumulation, lipid body formation, and acyl coenzyme A oxidases of the yeast Yarrowia lipolytica. Applied and environmental microbiology. 70, 3918-24.

Mukhopadhyay, A., Redding, A. M., Rutherford, B. J., Keasling, J. D., 2008. Importance of systems biology in engineering microbes for biofuel production. Current opinion in biotechnology. 19, 228-34.

Nakatogawa, H., Suzuki, K., Kamada, Y., Ohsumi, Y., 2009. Dynamics and diversity in autophagy mechanisms: lessons from yeast. Nat. Rev. Mol. Cell. Biol. 10, 458-67.

Ntambi, J. M., Miyazaki, M., Stoehr, J. P., Lan, H., Kendziorski, C. M., Yandell, B. S., Song, Y., Cohen, P., Friedman, J. M., Attie, A. D., 2002. Loss of stearoyl-CoA desaturase-1 function protects mice against adiposity. Proc Natl Acad Sci USA. 99, 11482-6.

Papanikolaou, S., Aggelis, G., 2002. Lipid production by Yarrowia lipolytica growing on industrial glycerol in a single-stage continuous culture. Bioresource technology. 82, 43-9.

Papanikolaou, S., Chevalot, I., Komaitis, M., Marc, I., Aggelis, G., 2002. Single cell oil production by Yarrowia lipolytica growing on an industrial derivative of animal fat in batch cultures. Applied microbiology and biotechnology. 58, 308-12.

Peralta-Yahya, P. P., Keasling, J. D., 2010. Advanced biofuel production in microbes. Biotechnology journal. 5, 147-62.

Ratledge, C., 2014. The role of malic enzyme as the provider of NADPH in oleaginous microorganisms: a reappraisal and unsolved problems. Biotechnology letters. 36, 1557-68.

Sarkar, S., Ravikumar, B., Floto, R. A., Rubinsztein, D. C., 2009. Rapamycin and mTOR-independent autophagy inducers ameliorate toxicity of polyglutamine-expanded huntingtin and related proteinopathies. Cell death and differentiation. 16, 46-56.

Scaglia, N., Chisholm, J. W., Igal, R. A., 2009. Inhibition of stearoylCoA desaturase-1 inactivates acetylCoA carboxylase and impairs proliferation in cancer cells: role of AMPK. PloS one. 4, e6812.

Seglen, P. O., Gordon, P. B., 1982. 3-Methyladenine: specific inhibitor of autophagic/lysosomal protein degradation in isolated rat hepatocytes. Proc Natl Acad Sci USA. 79, 1889-92.

Service, R. F., 2008. Biofuels. Eyeing oil, synthetic biologists mine microbes for black gold. Science. 322, 522-3.

Singh, A., Nigam, P. S., Murphy, J. D., 2011. Renewable fuels from algae: an answer to debatable land based fuels. Bioresource technology. 102, 10-6.

Steen, E. J., Kang, Y., Bokinsky, G., Hu, Z., Schirmer, A., McClure, A., Del Cardayre, S. B., Keasling, J. D., 2010. Microbial production of fatty-acid-derived fuels and chemicals from plant biomass. Nature. 463, 559-62.

Stephanopoulos, G., Abidi, S. H. I., 2010. Production of advanced biodiesel using renewable feedstocks. Int Sugar J. 112, 134-136.

Swan, T. M., Watson, K., 1999. Stress tolerance in a yeast lipid mutant: membrane lipids influence tolerance to heat and ethanol independently of heat shock proteins and trehalose. Canadian journal of microbiology. 45, 472-9. 
Swinnen, J. V., Vanderhoydonc, F., Elgamal, A. A., Eelen, M., Vercaeren, I., Joniau, S., Van Poppel, H., Baert, L., Goossens, K., Heyns, W., Verhoeven, G., 2000. Selective activation of the fatty acid synthesis pathway in human prostate cancer. International journal of cancer. Journal international du cancer. 88, 176-9.

Tai, M., Stephanopoulos, G., 2013. Engineering the push and pull of lipid biosynthesis in oleaginous yeast Yarrowia lipolytica for biofuel production. Metabolic engineering. 15, 1-9.

Takeshige, K., Baba, M., Tsuboi, S., Noda, T., Ohsumi, Y., 1992. Autophagy in yeast demonstrated with proteinase-deficient mutants and conditions for its induction. The Journal of cell biology. 119, 30111.

Wakil, S. J., Stoops, J. K., Joshi, V. C., 1983. Fatty acid synthesis and its regulation. Annual review of biochemistry. 52, 537-79.

You, K. M., Rosenfield, C. L., Knipple, D. C., 2003. Ethanol tolerance in the yeast Saccharomyces cerevisiae is dependent on cellular oleic acid content. Applied and environmental microbiology. 69, 1499-1503.

Yousuf, A., Sannino, F., Addorisio, V., Pirozzi, D., 2010. Microbial Conversion of Olive Oil Mill Wastewaters into Lipids Suitable for Biodiesel Production. J Agr Food Chem. 58, 8630-8635.

Zhang, F., Rodriguez, S., Keasling, J. D., 2011. Metabolic engineering of microbial pathways for advanced biofuels production. Current opinion in biotechnology. 22, 775-83.

Zhao, C. H., Cui, W., Liu, X. Y., Chi, Z. M., Madzak, C., 2010. Expression of inulinase gene in the oleaginous yeast Yarrowia lipolytica and single cell oil production from inulin-containing materials. Metabolic engineering. 12, 510-7. 
Table 1. Plasmids and strains used in the study.

\begin{tabular}{|c|c|c|}
\hline $\begin{array}{l}\text { Strains (host } \\
\text { strain) }\end{array}$ & Genotype or plasmid & Source \\
\hline \multicolumn{3}{|l|}{ E. coli } \\
\hline DH5 $\alpha$ & $\begin{array}{l}\text { fhuA2 } \Delta(\arg F-l a c Z) U 169 \text { phoA glnV44 } \$ 80 \Delta(\text { lacZ)M15 gyrA96 } \\
\text { recAl relAl endAl thi-1 hsdR17 }\end{array}$ & Invitrogen \\
\hline \multicolumn{3}{|c|}{ 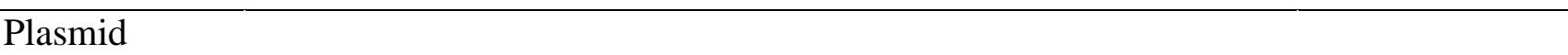 } \\
\hline YLEX & pINA1269 -LEU & Yeastern \\
\hline pMT015 & YLEX php4d ::TEFin & $\begin{array}{l}\text { (Tai and } \\
\text { Stephanopoulos, } \\
\text { 2013) }\end{array}$ \\
\hline pMT053 & TEFin-DGA1 & $\begin{array}{l}\text { (Tai and } \\
\text { Stephanopoulos, } \\
\text { 2013) }\end{array}$ \\
\hline pMT065 & TEFin-DGA1, hp4d-ACC1 & $\begin{array}{l}\text { (Tai and } \\
\text { Stephanopoulos, } \\
\text { 2013) }\end{array}$ \\
\hline pQK7 & pMT15 LEU::hygromycin & This work \\
\hline pQK27 & YLEX php4d-SCD & This work \\
\hline pQK31 & YLEX TEFin-ACC1; TEFin-DGA1 & This work \\
\hline pQK32 & pQK7 TEFin-SCD & This work \\
\hline \multicolumn{3}{|l|}{ Y. lipolytica } \\
\hline YL-wt & MATa, leu2-270, ura3-302::URA3, xpr2-332, axp-2, LEU2 & This work \\
\hline YL-D9 & $\begin{array}{l}\text { MATa, leu2-270, ura3-302::URA3, xpr2-332, axp-2, hp4d-SCD- } \\
\text { LEU2 }\end{array}$ & This work \\
\hline MTYL065 & $\begin{array}{l}\text { MATa, leu2-270, ura3-302::URA3, xpr2-332, axp-2, hp4d- } \\
\text { ACC1, TEFin-DGA1-LEU2 }\end{array}$ & $\begin{array}{l}\text { (Tai and } \\
\text { Stephanopoulos, } \\
\text { 2013) }\end{array}$ \\
\hline YL-hr3 & $\begin{array}{l}\text { MATa, leu2-270, ura3-302::URA3, xpr2-332, axp-2, hp4d- } \\
\text { ACC1, TEFin-DGA1, hp4d-SCD-LEU2 }\end{array}$ & This work \\
\hline YL-ad9 & $\begin{array}{l}\text { MATa, leu2-270, ura3-302::URA3, xpr2-332, axp-2, TEFin- } \\
\text { ACC1, TEFin-DGA1-LEU, TEFin-SCD-Hyg }\end{array}$ & This work \\
\hline
\end{tabular}




\section{Figure Legends}

Figure 1. Improvement of lipid production in $Y$. lipolytica by overexpression of SCD identified by reverse engineering mouse fat-storing tissues. (A) Relative digital gene expression counts of known fatty acid and lipid biosynthetic/modulating genes in fat storing and non-fat storing tissues in mice: SCD, stearoyl-CoA desaturase; ACC1, acetyl-CoA carboxylase 1; DGAT1, diacylglycerol O-acyltransferase 1; FAS, fatty acid synthase; ACSL1, acyl-CoA synthetase longchain family member 1. (B) Implementation of SCD overexpression led to improved biomass and lipid production. The YL-wt, MTYL065, YL-hr3 and the YL-ad9 cells were grown to stationary phase (120 hours) under nitrogen limiting medium (carbon to nitrogen ratio $=100$ ) in shake flask culturing. Data are mean $+/-$ SD for three biological replicates.

Figure 2. Fermentation characteristics of YL-wt and YL-ad9 strains. (A) Growth and FAME production profiles of YL-wt. (B) Growth and FAME production profiles of YL-ad9 strain cultivation in 1.5-L-bioreactor. Total sugar consumed and lipid produced by YL-ad9 strain shown here for 78 hours of fermentation period. The fermentation run was supplemented twice during 42 - 65 h. In total, $229.3 \mathrm{~g} / \mathrm{l}$ sugar was consumed and $55 \mathrm{~g} / \mathrm{L}$ FAME was produced in 78 hours. Data are mean $+/$ - SD for two replicate bioreactor runs. (C, D) Imaging analyses for the morphology of YL-wt and YL-ad9 strains. The stationary phase YL-ad9 and YL-wt cells from an earlier 2Lfermentation experiment was used as seed inoculums in fresh batch fermentation. (E, F) Imaging analyses for intracellular TAG mobilization. The YL-ad9 and YL-wt inoculums cells were grown to log phase (42 h) and stained with nile red dye for neutral lipid staining. The scale bars represent $6 \mu \mathrm{m}$.

Figure 3. Proposed mechanism of SCD -mediated de-regulation of fatty acid pathway in oleaginous yeast Yarrowia lipolytica. Step 1: Acetyl-CoA, the precursor molecule for fatty acid 
synthesis is converted to malonyl-CoA via Acetyl-CoA carboxylase (ACC1), which in turn is converted to saturated palmitoyl-CoA and stearoyl-CoA via fatty acid synthases (FASs). Step 2: Both saturated fatty acids are potent inhibitors of ACC1 inhibition. Steps 3 and 4: SCD draws fatty acid flux in forward direction by converting C16 and C18 saturated fatty acyl-CoAs into monounsaturated oleoyl-CoA. However, oleoyl-CoA is also a potent inhibitor of SCD (MinvilleWalz et al., 2012), keeping the fatty acid flux under stringent steady state control. Step 5 and 6 : Over-expression of SCD disturbs the intrinsic regulatory balance toward monounsaturated oleoylCoA synthesis, however, a sink is required to prevent fatty acid accumulation and allosteric inhibition. This is achieved by sequestering increased fatty acid synthesis towards membrane biogenesis during growth (log phase) and towards intracellular TAG biosynthesis and storage upon nutrient depletion (stationary phase) leading to extreme obesity evident in oleaginous yeast.

Figure 4. Performances of YL-ad9 strain in bioreactor using biomass hydrolysate and industrial glycerol. (A). Growth and TAG produced (shown as FAME) by YL-ad9 and YL-wt strain in biomass hydrolysate. Robust growth was observed for YL-ad9 with 20 hour of lag phase. YL-wt failed to grow under similar conditions. (B) The growth and FAME output using glycerol as sole carbon source. The YL-ad9 strain grown on $150 \mathrm{~g} / \mathrm{l}$ crude industrial glycerol without detoxification procedure. Data are mean +/- SD for two replicate bioreactor runs.

Figure 5. Autophagic responses in oleaginous yeast. (A) Transmission electron microscopic images of YL-ad9 cells harvested at the exponential growth phase ( $42 \mathrm{~h}$ ) and the stationary phase $(120 \mathrm{~h})$ of shake flask fermentation under lipid producing media. The scale bars represent $500 \mathrm{~nm}$. The differential interference contrast microscopic and fluorescence microscopic images of (B) the untreated YL-ad9 cells; (C) YL-ad9 cells treated with stained with $10 \mathrm{mM}$ 3-methyl adenine autophagic inhibitor; (D) YL-ad9 treated with rapamycin $(0.3 \mathrm{ug} / \mathrm{ml})$. All YL-ad9 cells were 
stained with nile red before being viewed under florescent microscope along with DIC imaging. The scale bars represent $6 \mu \mathrm{m}$. 
A

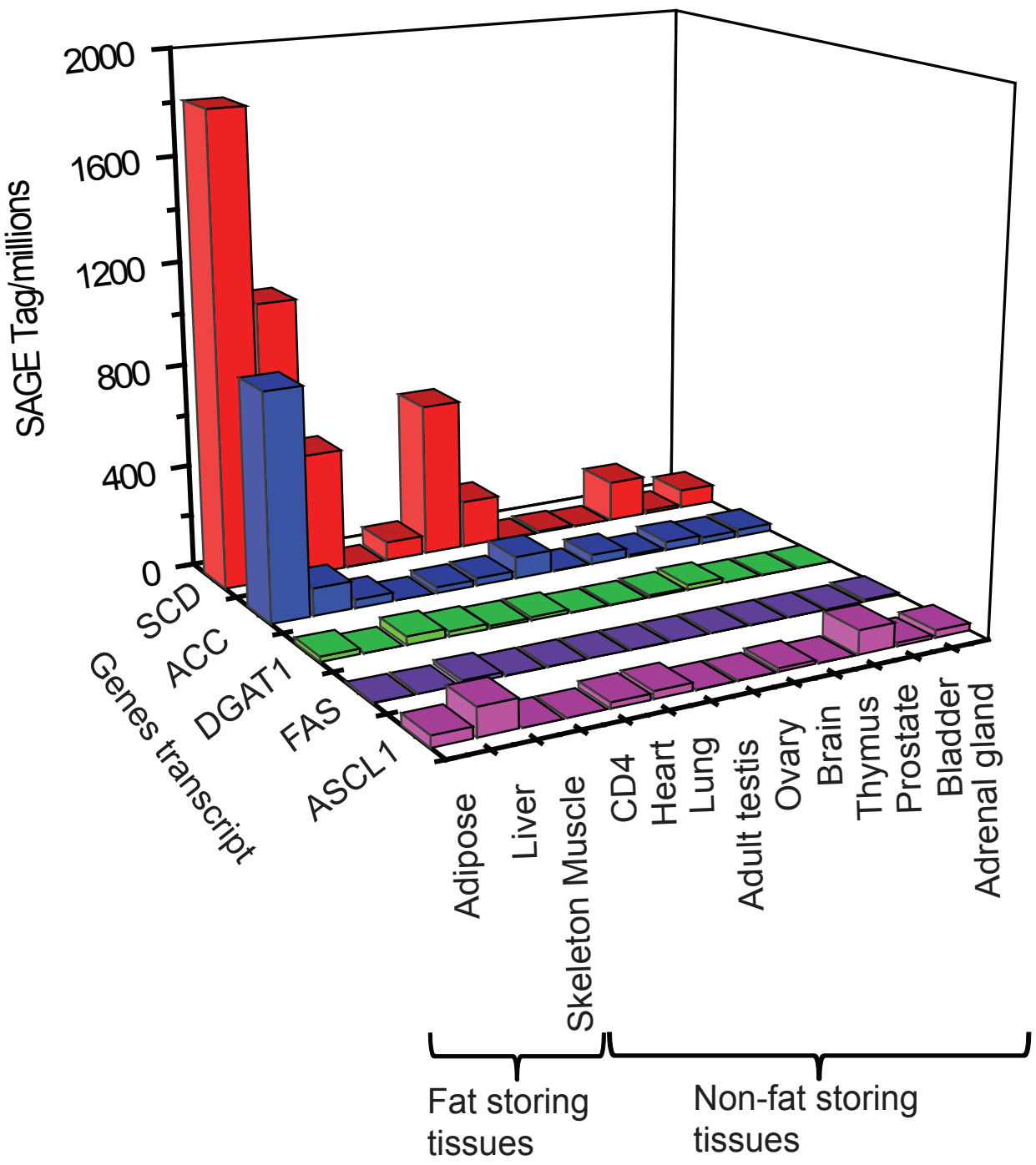

B

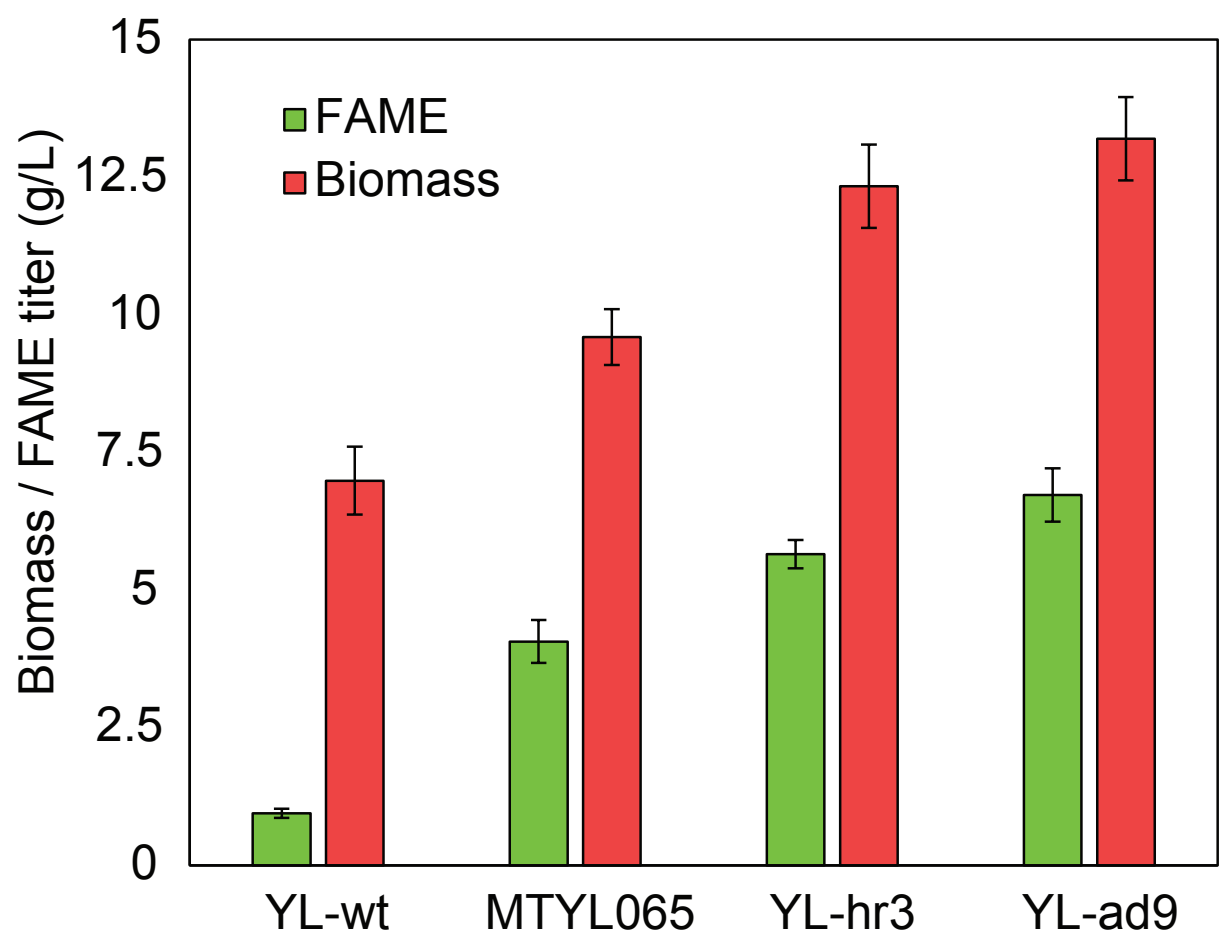


Figure 2

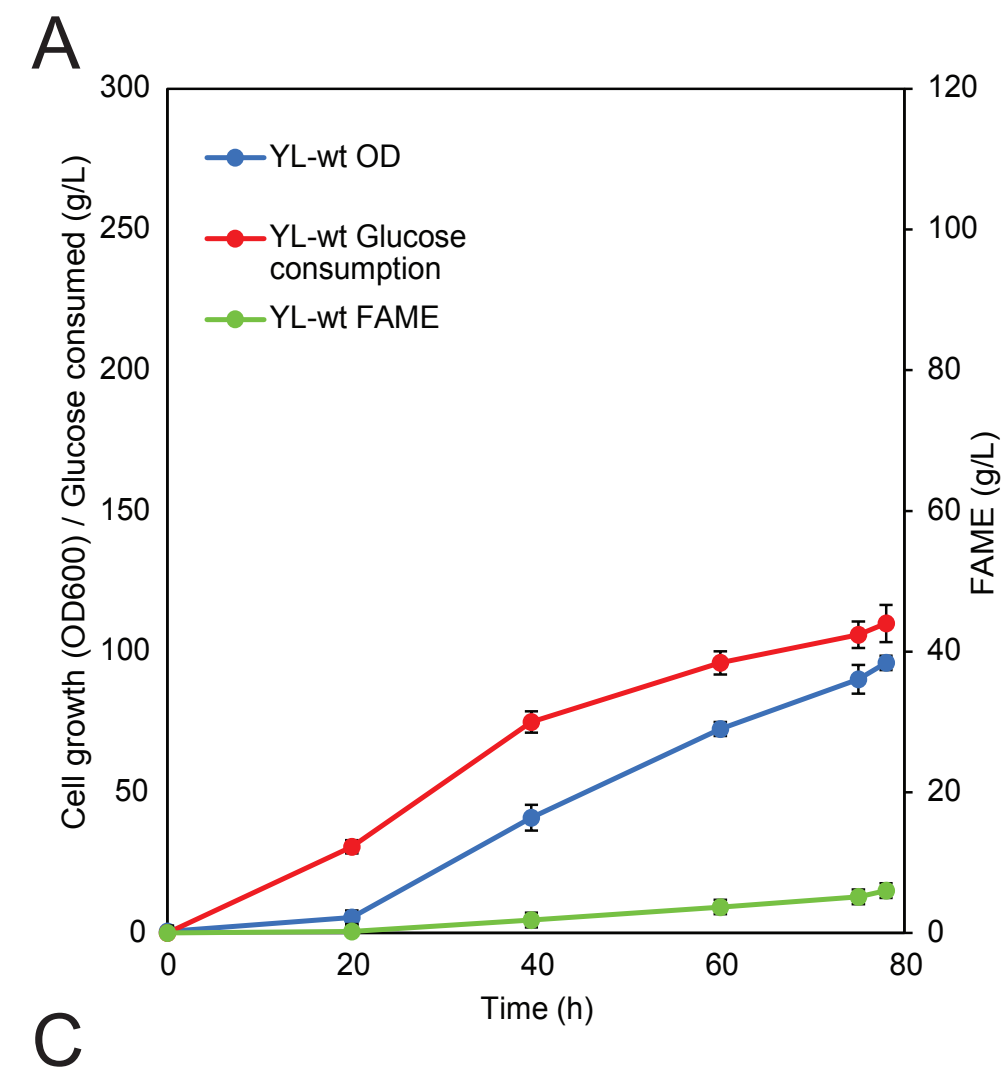

B
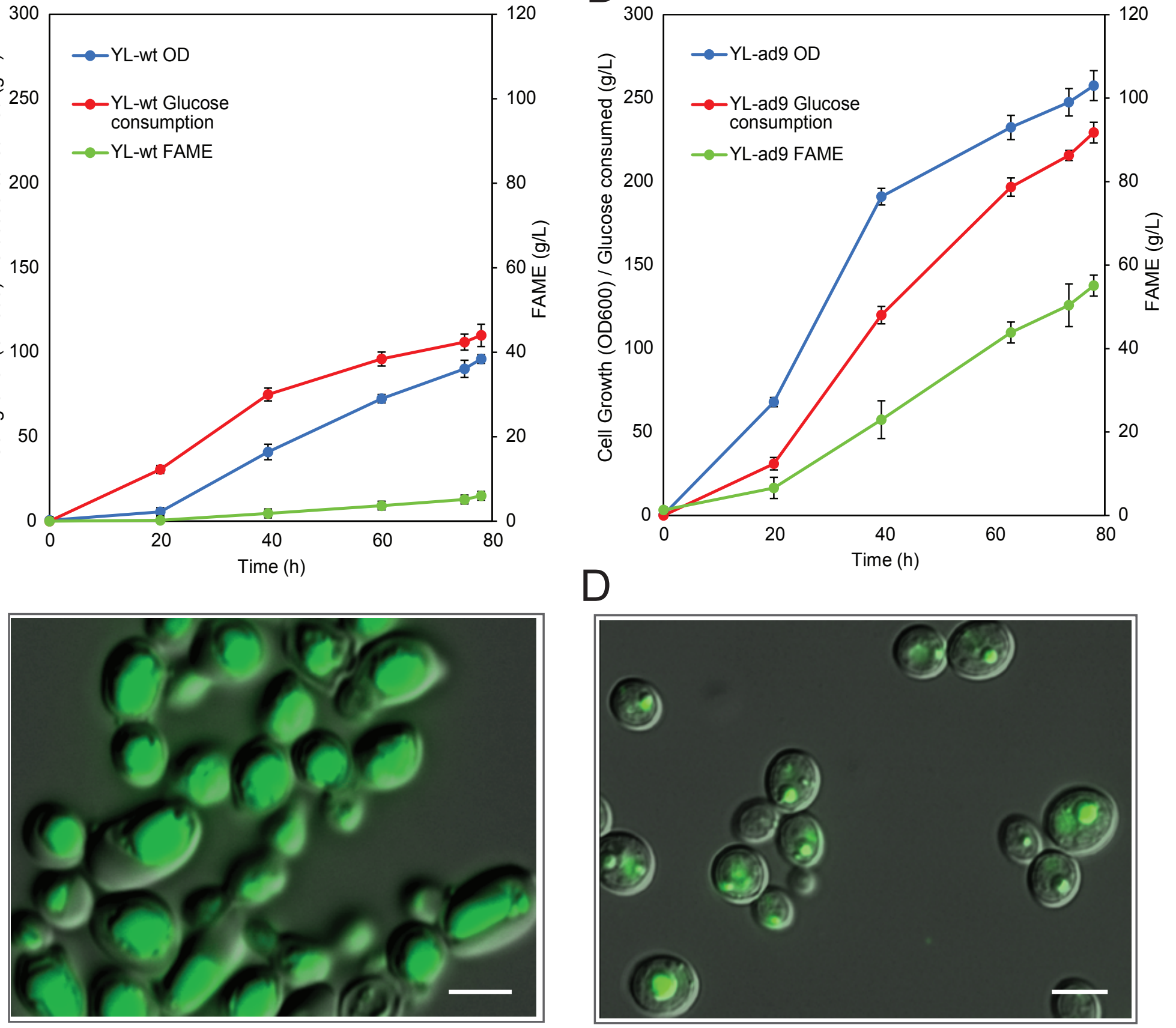

E

F
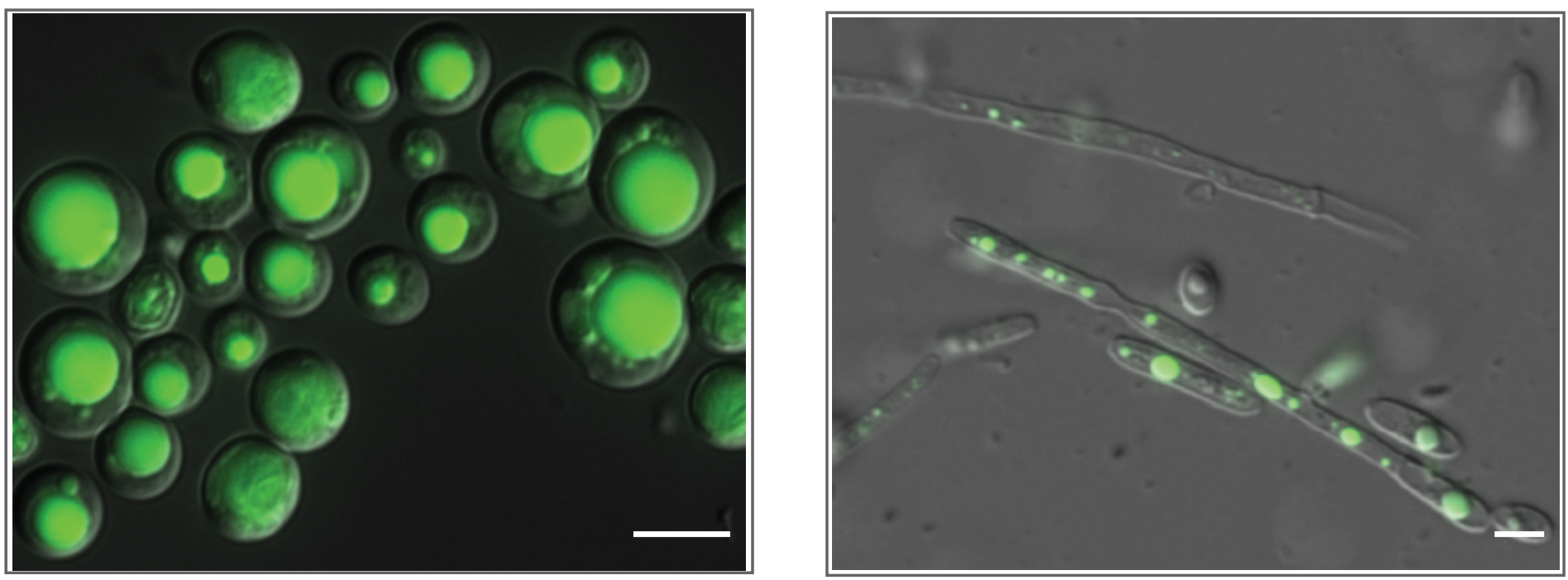


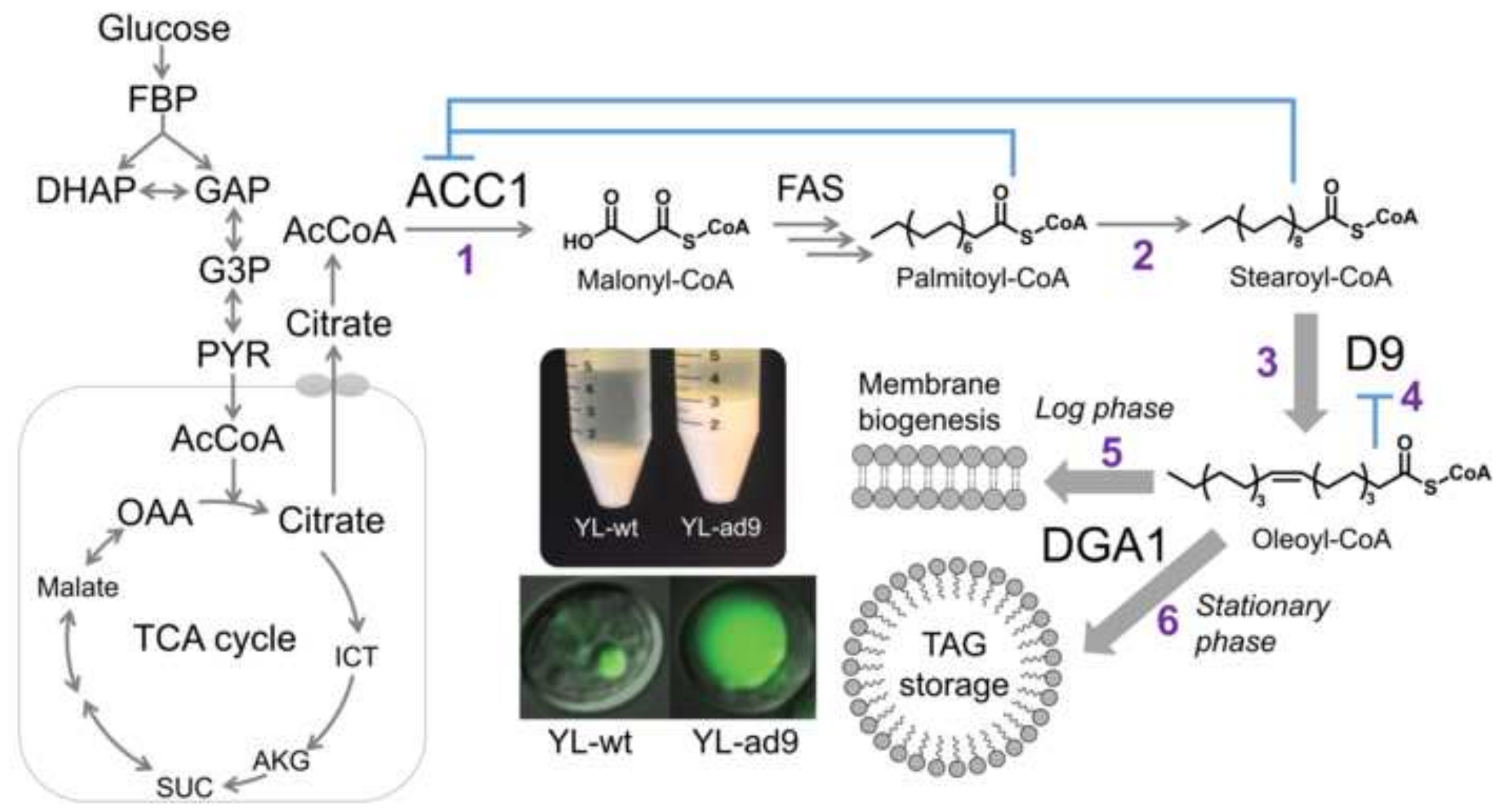


${ }^{\text {Figurg }} 4$

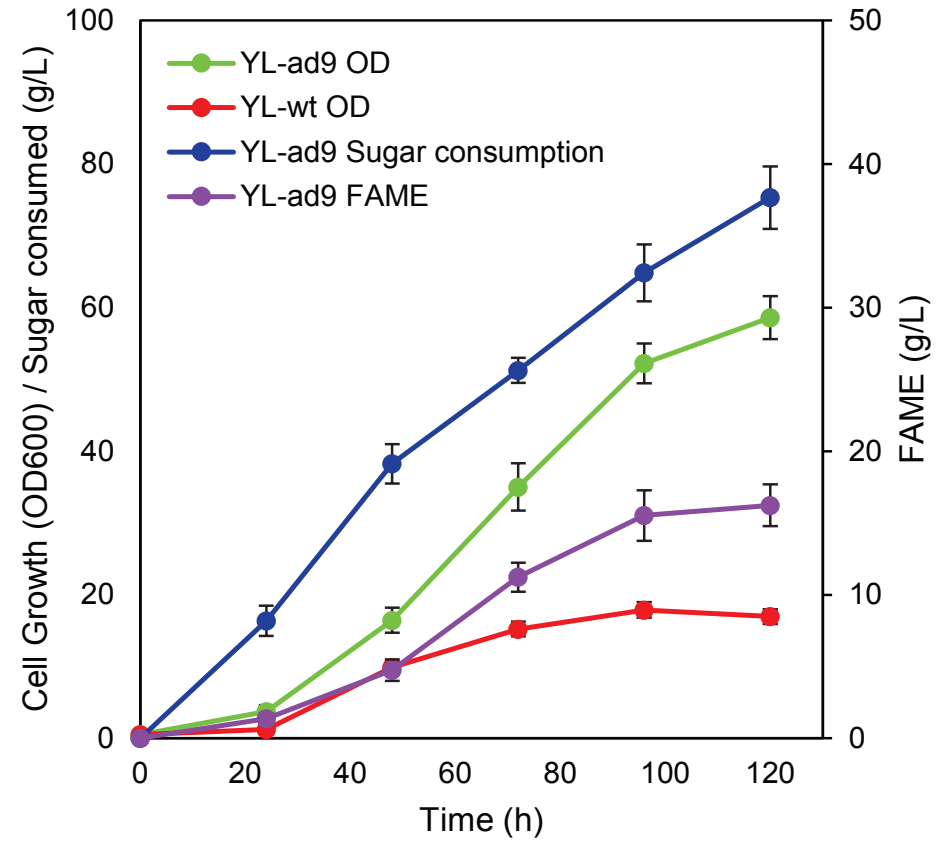

B

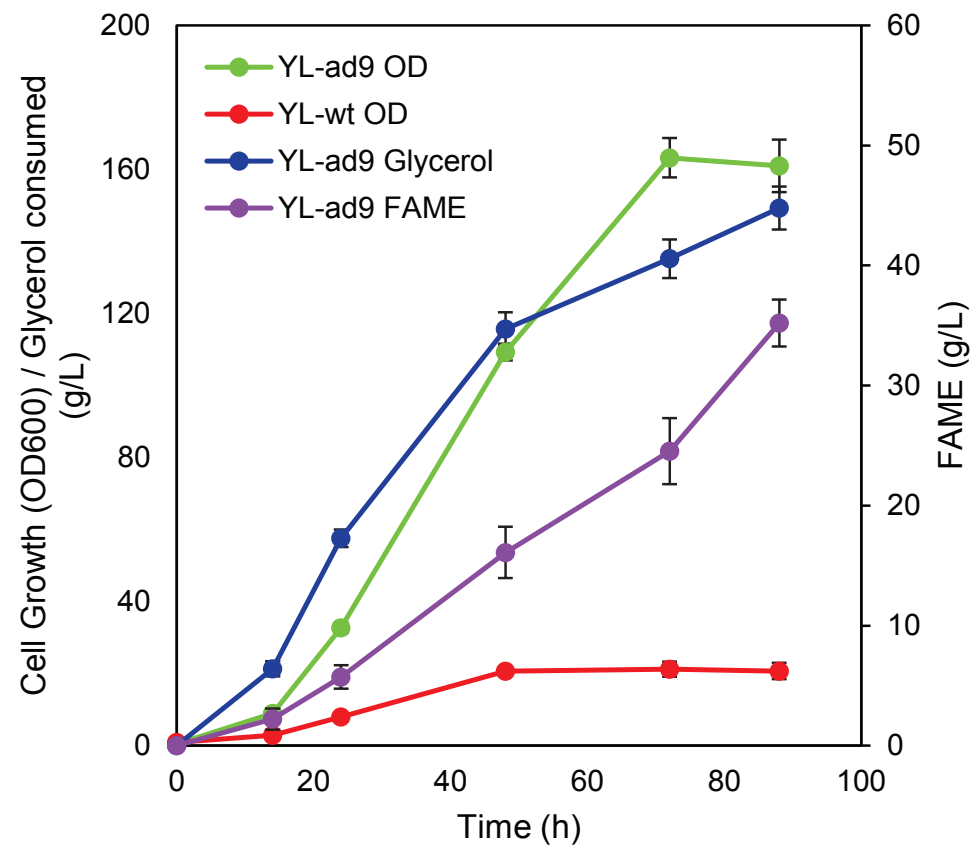




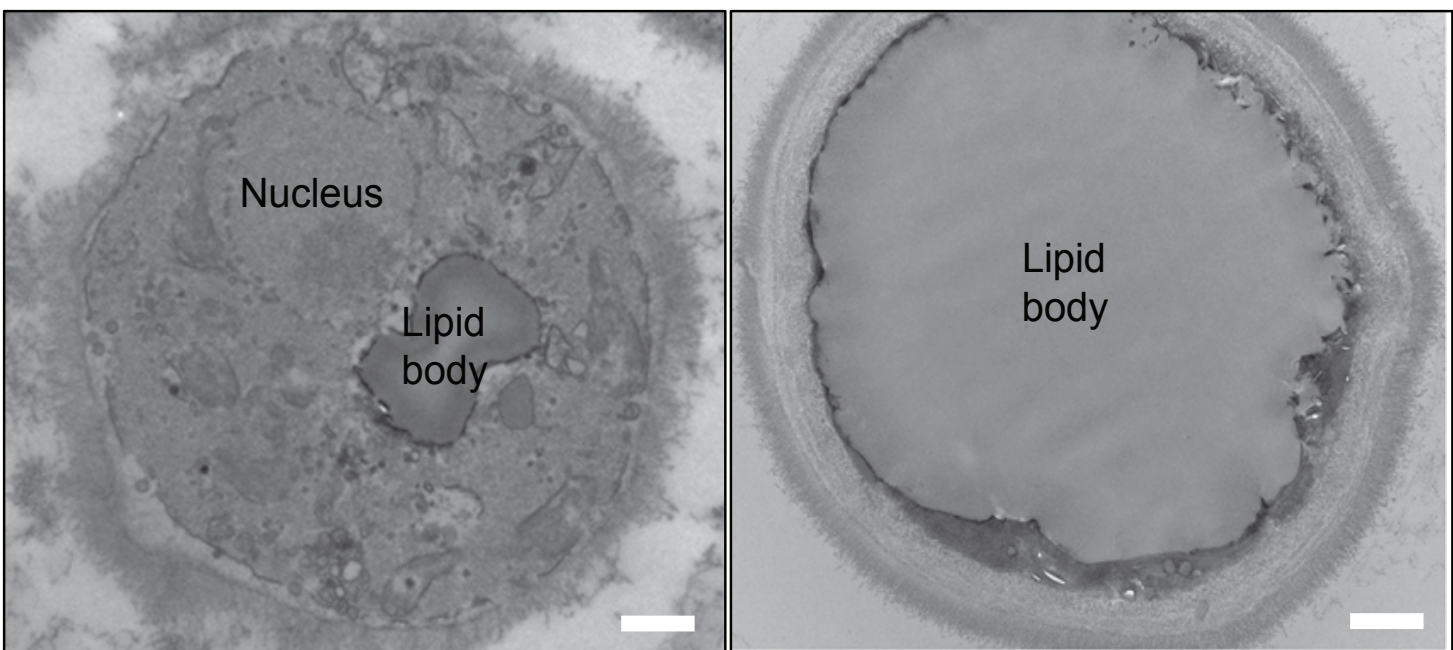

YL-ad9 (28 h, log growth phase) $\quad$ YL-ad9 (78 h, stationary phase)

B

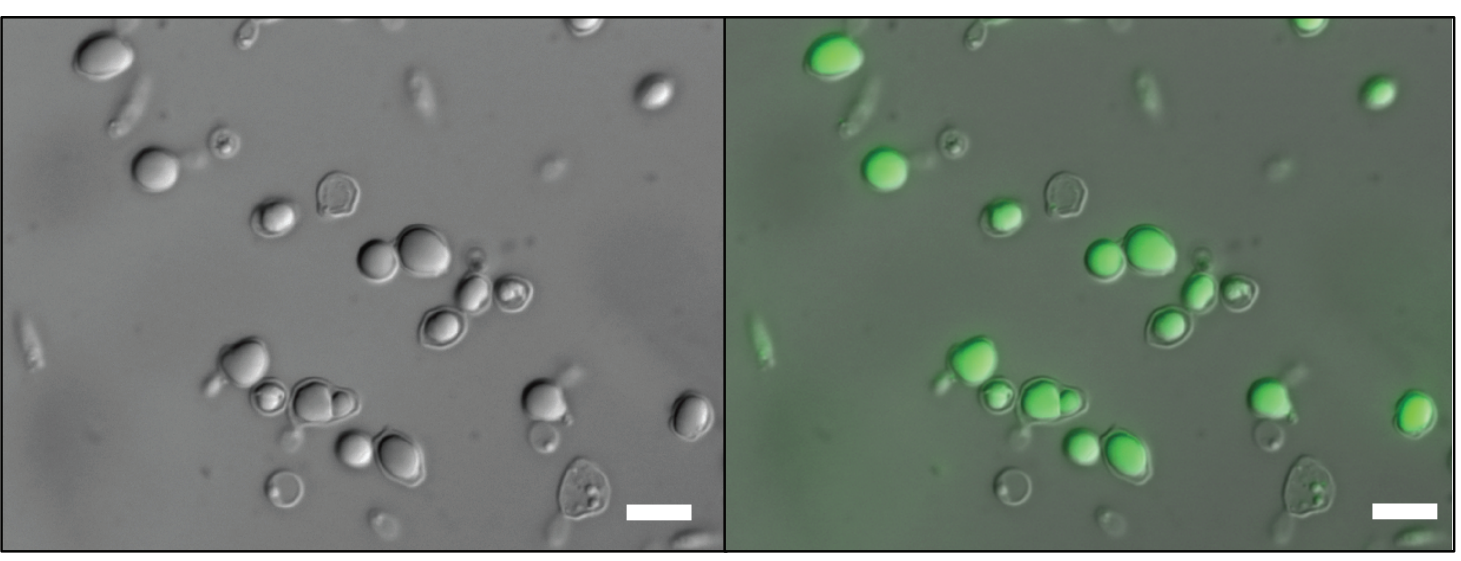

0

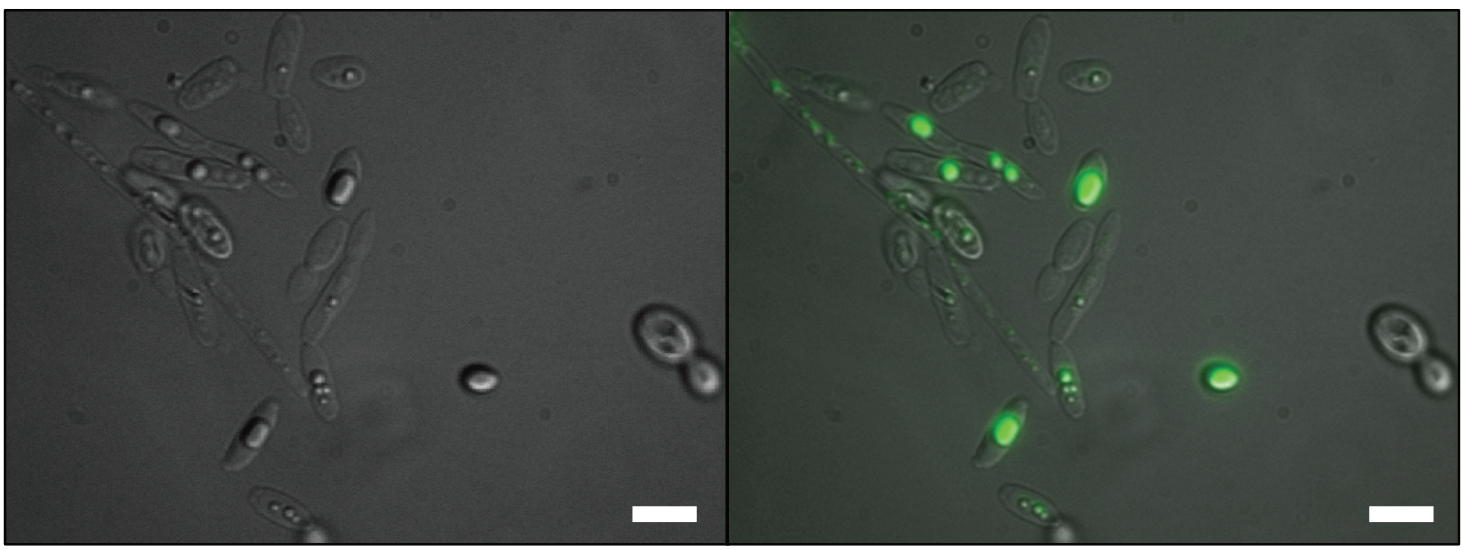

$\mathrm{D}$

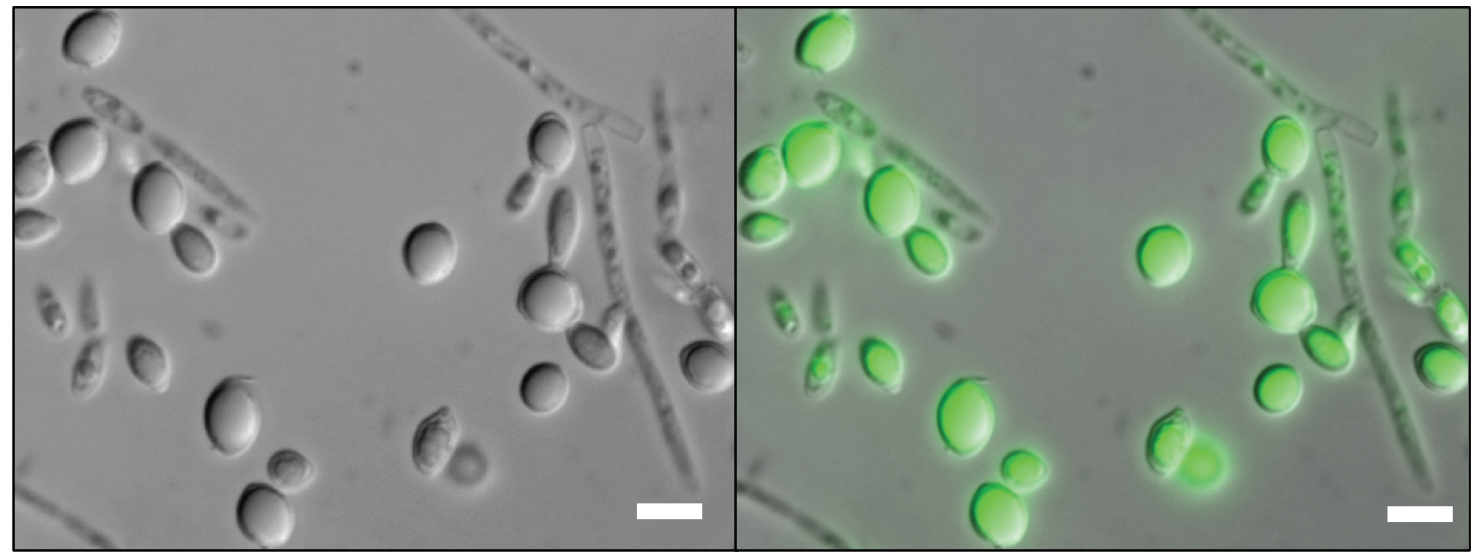

